\title{
EFFECTS OF VERBALIZATION ON DISGRIMINATION AND REVERSAL LEARNING IN NORMAL AND SUBNORMAL GHILDREN
}

\author{
TOYOBU WATANABE AND JOAN RAWLINSON \\ Kyoto Prefectural University Prestwich Hospital, Manchester
}

\begin{abstract}
Normal and subnormal children were given a size discrimination and its reversal tasks. They were equally subdivided into groups of high and low language comprehension ability on the basis of their Sentence Comprehension Test (SCT) scores. The results indicated that the child's SCT scores can be a good predictor of his performance on the reversal task. For normal Ss with low SCT scores, the results supported the view of $O^{\prime}$ Connor and Hermelin that reinforcement of child's verbalization leads to stable and persistent response set which has an interfering effect on reversal shift. It is suggested that the data may be interpreted in terms of a production deficiency hypothesis. This experiment failed to replicate the O'Connor and Hermelin finding that subnormal children perform a reversal shift better than matched normal peers.
\end{abstract}

The role of verbal mediators in children's learning seems to be less simple than has previously been realized. A recent review by Stevenson (1970) described that there are at least three stages in the role of verbalization: (1) the child may not have the words that are necessary to direct behavior, (2) he may acquire the words but not use them, and (3) he may have the words and use them appropriately. In relation to these problems, Reese (1962) called attention to the possibility of mediational deficiency in young children, and pointed out that there is a stage in ontogenesis during which the child tends not

1 This research was carried out while the first author was a visiting professor at the Hester Adrian Research Centre, Manchester, England, 1973.Greatful acknowledgement is made to Professor Peter Mittler, Dr. James Hogg, and Mr. Kevin Wheldall for their invaluable assistance in planning and executing this research. The authors wish to thank St. Peter's R. C. Infants School, Leacroft Special School, and Margaret Whitehead School, for making this study possible. We are further greatful to Professor A. D. B. Clarke, University of Hull, for his kind advice and encouragement throughout this research. to mediate or regulate his overt behavior verbally, despite the fact he is able to understand and correctly use the words in question. Maccoby (1964), however, suggested that younger children can make use of verbal mediations if verbal labels are explicitly brought into experimental situation but that they usually will not produce them spontaneously, even if they 'know' the words in question. In attempt to clarify this, Flavell, Beach, and Chinsky (1966), and Keeney, Cannizzo, and Flavell (1967) proposed that a distinction can be made between alternative hypotheses. One hypothesis, which could properly be called the mediational deficiency, would imply that verbal responses were made, but that these tended not to mediate performance effectively. An alternative, which could be called the production deficiency, would imply that verbal responses tended not to be made as potential mediators of child's task behavior. Recently Bem (1970) proposed three-stage processes in children's problem solving: comprehension, production, and mediation. According to this hypothesis, it is during the first stage, comprehension, that the child pre- 
sumably discovers what verbalization or self-instruction to produce.

It is a particularly interesting problem to clarify whether the verbalization facilitates or prohibits the child's performance in the production deficiency period. In the Kendler, Kendler, and Wells study (1960) no effect of verbalization on reversal shift was demonstrated for three to five years old children, however in the Kendler and Kendler study (1962) there was a trend for performance on reversal in four year olds to be facilitated by verbalization. It thus appears that the effect of verbalization is equivocal. On the other hand, O'Connor and Hermelin (1959) found that severely subnormal children learned a reversal of two stimulus discrimination faster than normal subjects matched for MA, and that severely subnormal children who were required to verbalize their choices on the original discrimination showed retardation rather than facilitation on the reversal. O'Connor and Hermelin concluded that while conditioning tasks takes place more quickly under the influences of verbal system than under no such influences, the connections thus developed are less mobile than those established under the direct signal alone. The lack of verbal regulation of motor responses in severely subnormal children seemed to result in unstable responses which could be rapidly reversed. Their observations indicated that verbal mediation may have a negative and interfering effect. In a recent review of this area in subnormal children Heal and Johnson (1970) concluded that mentally subnormal children were inferior to their MA matched peers in ability to reverse. Unusual among the results was the finding of O'Connor and Hermelin that showed subnormal children to be superior in reversal. In the same context, Luria (1961) suggested that the mentally subnormal may have mediational deficits so that the verbal system fails to connect with the motor system. According to his view, active verbalization by the subnormal children may facilitate mediation, and their performances would be more similar to those of the normal children. This effect was demonstrated but was confounded because the mediating status of normal children was not clear.

The purposes of this study are as follows: (1) on the basis of previous studies, it is reasonable to assume that the ability to use verbal mediation is strongly linked to linguistic development. Therefore, an attempt is made to examine whether the language comprehension test can be useful in assessing the 'mediational status' of a child, (2) the experiment examines the hypothesis that there is a stage in normal development during which reinforcement of verbalization has an interfering effect on the performance in reversal shift, and (3) the experiment replicates the O'Connor and Hermelin finding that subnormal children perform a discrimination reversal task better than their nondeficient peers.

\section{MethoD}

\section{Subjects}

The subjects were 20 normal children attending a nursery school and 20 mentally subnormal children attending two local special schools in Manchester. Their vocabulary ages (VA) by the English Picture Vocabulary Test (EPVT) ranged from 34 to 76 months in normal subjects and 38 to 79 months in subnormal subjects. They were equally subdivided into groups of high and low abilities on the basis of their median Sentence Comprehension Test (SCT) scores. $\mathrm{SCT}$, originally devised with A. Hobsbaum at Birkbeck College, London, is a new experimental test giving more extensive evaluation of a child's sentence comprehension ability (Mittler \& Wheldall, 1971). The test requires the child to identify by pointing which of three or four pictures corresponds to a stimulus sentence spoken by the tester. Sentences vary in grammatical structure, and include simple intransitives; comparatives and superlatives; sentences containing subject, verb, and object ; 
TABLE 1

Means and standard deviations of CA, VA, and total SGT score

\begin{tabular}{|c|c|c|c|c|c|c|c|}
\hline \multirow{2}{*}{ Group } & \multirow{2}{*}{$\mathcal{N}$} & \multicolumn{2}{|c|}{$\mathrm{CA}$} & \multicolumn{2}{|c|}{ VA } & \multicolumn{2}{|c|}{ Total SCT Score } \\
\hline & & $M$ & $S D$ & $M$ & $S D$ & $M$ & $S D$ \\
\hline \multicolumn{8}{|l|}{ Normal } \\
\hline High scorers & 10 & 49.7 & 5.1 & 63.1 & 8.6 & 43.6 & 4.0 \\
\hline Low scorers & 10 & 43.6 & 4.9 & 51.2 & 11.0 & 32.3 & 4.4 \\
\hline \multicolumn{8}{|l|}{ Subnormal } \\
\hline High scorers & 10 & 151.1 & 37.6 & 69.0 & 13.3 & 45.4 & 3.6 \\
\hline Low scorers & 10 & 131.4 & 39.0 & 50.6 & 9.2 & 27.9 & 5.5 \\
\hline
\end{tabular}

negatives, passives, past and future tenses, prepositions and embedded clauses. Four examples of each of the 15 sentence types are given, making a possible total of 60 . Table 1 shows the means and standard deviations for CA, VA, and SCT scores in each group.

\section{Materials and Apparatus}

$3.0 \times 3.0 \mathrm{~cm}$ and $3.5 \times 3.5 \mathrm{~cm}$ black squares were used as stimuli. They were back-projected on to ground glass display pannels of a Teddington touch tutor. When the child touched the correct stimulus, a smartie was dispensed as a reinforcer. Following a response it was possible either to maintain the display or to present the next slide.

\section{Procedure}

All children were given a two-choice discrimination and its reversal tasks. In the original learning, subjects were received one of the two experimental treatments. In the 'no-verbalization' treatment, the child was seated in front of the machine and told that he could win smarties by touching one of the squares, and that tried to get as many smarties as he could. If he touched the correct stimulus, a smartie was dispensed. The child was told, "See, you have won a smartie." The next stimuli were presented, and the procedure was repeated with a non-correction method. The subject was trained to a criterion of ten consecutive correct responses. In the 'verbalization' treatment, the child was seated and told to try to get smarties. If he made a correct response, a smartie was dispensed and the experimenter said, "See, you have won a smartie." The stimuli were retained and the child was asked, "Which one did you touch?" Often the child would say, "The big one" or "The small one" as appropriate. However, if such a response was not forthcoming, the experimenter asked, "Was it the big one or the small one?" When the child had given the correct answer, the experimenter said, "That's right, good, it's the big/small one", and proceeded to the next trial. The non-correction was also used. The learning criterion was the same as that in the no-verbalization treatment.

Immediately after the original learning, the subjects were shifted reversal learning under the same procedure for all groups. The stimulus which had previously been negative became now positive. A smartie reinforcer was given when subjects made a correct response. No comment was made by the experimenter at any point during the reversal. Reversal trials were terminated when the subject reached a criterion of ten consecutive correct responses.

As already described, all subjects were divided subgroups on the basis of their performances on SCT. For each subgroup, half the children were given the verbalization treatment, and the remaining subjects were given the no-verbalization treatment. For half the children the positive stimulus was the large square in the original discrimination and for the other children the small square was positive. The position of correct stimuli were determined by the Gellermann's series. 
TABLE 2

Mean number of trials and errors to criterion on original and reversal tasks in normal and subnormal groups

\begin{tabular}{|c|c|c|c|c|c|c|c|c|}
\hline \multirow{3}{*}{ Group } & \multicolumn{4}{|c|}{ Discrimination } & \multicolumn{4}{|c|}{ Reversal } \\
\hline & \multicolumn{2}{|c|}{ Trials } & \multicolumn{2}{|c|}{ Errors } & \multicolumn{2}{|c|}{ Trials } & \multicolumn{2}{|c|}{ Errors } \\
\hline & $M$ & $S D$ & $M$ & $S D$ & $M$ & $S D$ & $M$ & $S D$ \\
\hline \multicolumn{9}{|l|}{ Normal } \\
\hline $\mathrm{H}-\mathrm{NV}$ & 17.4 & 10.45 & 4.0 & 5.04 & 17.4 & 4.89 & 3.2 & 1.60 \\
\hline $\mathrm{H}-\mathrm{V}$ & 13.6 & 3.31 & 1.4 & 0.48 & 15.0 & 4.04 & 2.8 & 0.74 \\
\hline L-NV & 18.6 & 8.45 & 3.6 & 2.15 & 15.0 & 0.89 & 3.2 & 0.98 \\
\hline$L-V$ & 15.0 & 1.09 & 2.6 & 1.01 & 47.6 & 8.30 & 14.2 & 2.40 \\
\hline \multicolumn{9}{|c|}{ Subnormal } \\
\hline $\mathrm{H}-\mathrm{NV}$ & 13.6 & 3.78 & 1.4 & 0.48 & 20.8 & 9.06 & 3.8 & 2.48 \\
\hline $\mathrm{H}-\mathrm{V}$ & 13.2 & 1.32 & 1.6 & 0.80 & 17.4 & 6.28 & 3.8 & 1.72 \\
\hline L-NV & 30.2 & 12.92 & 7.4 & 5.27 & 29.8 & 14.04 & 11.0 & 9.52 \\
\hline $\mathrm{L}-\mathrm{V}$ & 37.8 & 19.31 & 11.2 & 9.92 & 35.2 & 13.79 & 10.0 & 4.33 \\
\hline
\end{tabular}

Notes: $H$ indicates the subjects with high SCT scores and $\mathrm{L}$ those with low scores. V indicates verbalization during original discrimination and NV no-verbalization.

TABLE 3

Four-way analysis of variance for trials to criterion in discrimination and reversal (Log transformations)

\begin{tabular}{|c|c|c|c|c|}
\hline Source & $d f$ & $S S$ & $M S$ & $F$ \\
\hline Between & 39 & 2.592 & & \\
\hline Normal vs subnormal (A) & 1 & 0.118 & 0.118 & 3.189 \\
\hline High vs low SCT score (B) & 1 & 0.862 & 0.862 & $23.297 * *$ \\
\hline Verbalization vs no-verbalization (C) & 1 & 0.061 & 0.061 & 1.648 \\
\hline $\mathrm{A} \times \mathrm{B}$ & 1 & 0.097 & 0.097 & 2.621 \\
\hline $\mathrm{A} \times \mathrm{C}$ & 1 & 0.010 & 0.010 & 0.270 \\
\hline $\mathrm{B} \times \mathrm{C}$ & 1 & 0.215 & 0.215 & $5.810^{*}$ \\
\hline $\mathrm{A} \times \mathrm{B} \times \mathrm{C}$ & 1 & 0.030 & 0.030 & 0.810 \\
\hline Error (b) & 32 & 1.199 & 0.037 & \\
\hline Within & 40 & 1.467 & & \\
\hline Discrimination vs reversal (D) & 1 & 0.159 & 0.159 & $6.625 *$ \\
\hline$A \times D$ & 1 & 0.029 & 0.029 & 1.208 \\
\hline $\mathrm{B} \times \mathrm{D}$ & 1 & 0.002 & 0.002 & 0.083 \\
\hline $\mathrm{C} \times \mathrm{D}$ & 1 & 0.099 & 0.099 & 4.125 \\
\hline$A \times B \times D$ & 1 & 0.141 & 0.141 & $5.875^{*}$ \\
\hline $\mathrm{A} \times \mathrm{C} \times \mathrm{D}$ & 1 & 0.129 & 0.129 & $5.375^{*}$ \\
\hline $\mathrm{B} \times \mathrm{C} \times \mathrm{D}$ & 1 & 0.099 & 0.099 & 4.125 \\
\hline$A \times B \times C \times D$ & 1 & 0.059 & 0.059 & 2.458 \\
\hline Error (w) & 32 & 0.700 & 0.024 & \\
\hline
\end{tabular}

$* p<.05 \quad * * p<.01$ 


\section{Results}

Table 2 shows the means and standard deviations for number of trials and errors to criterion in original discrimination and reversal. Four-way analysis of variance was performed for number of trials to criterion by the log transformed data. The results are summarized in Table 3 . There were significant difference between children with high and low SCT scores $(p<.01)$ and original discrimination and reversal $(p<.05)$. Three interactions were also significant at the $5 \%$ level. The $\mathrm{B} \times \mathrm{C}$ interaction was due to the fact that verbalization had little effect for the subjects with high SCT scores, while it increased the total number of trials for the subjects with low scores. The $\mathrm{A} \times \mathrm{C} \times \mathrm{D}$ interaction reflected that normal children with ver- balization required fewer trials in discrimination than in reversal, and that subnormal children required more trials than the normal peers but no clear effect of verbalization was demonstrated. The $\mathrm{A}$ $\times \mathbf{B} \times \mathrm{D}$ interaction was due to the fact that the normal children with high SCT scores required very few trials for both discrimination and reversal, and that the low scorers required fewer trials in discrimination than in reversal. The subnormal high scorers required many trials for both discrimination and reversal. Although the result of analysis of variance for error scores was substantially similar to that of trials to criterion, significant $\mathrm{B} \times \mathrm{C}$ and $\mathrm{A} \times \mathrm{B} \times \mathrm{D}$ interactions were not found. This clearly underlines the complex relationship between trials and error scores, and may suggest some systematic bias which could
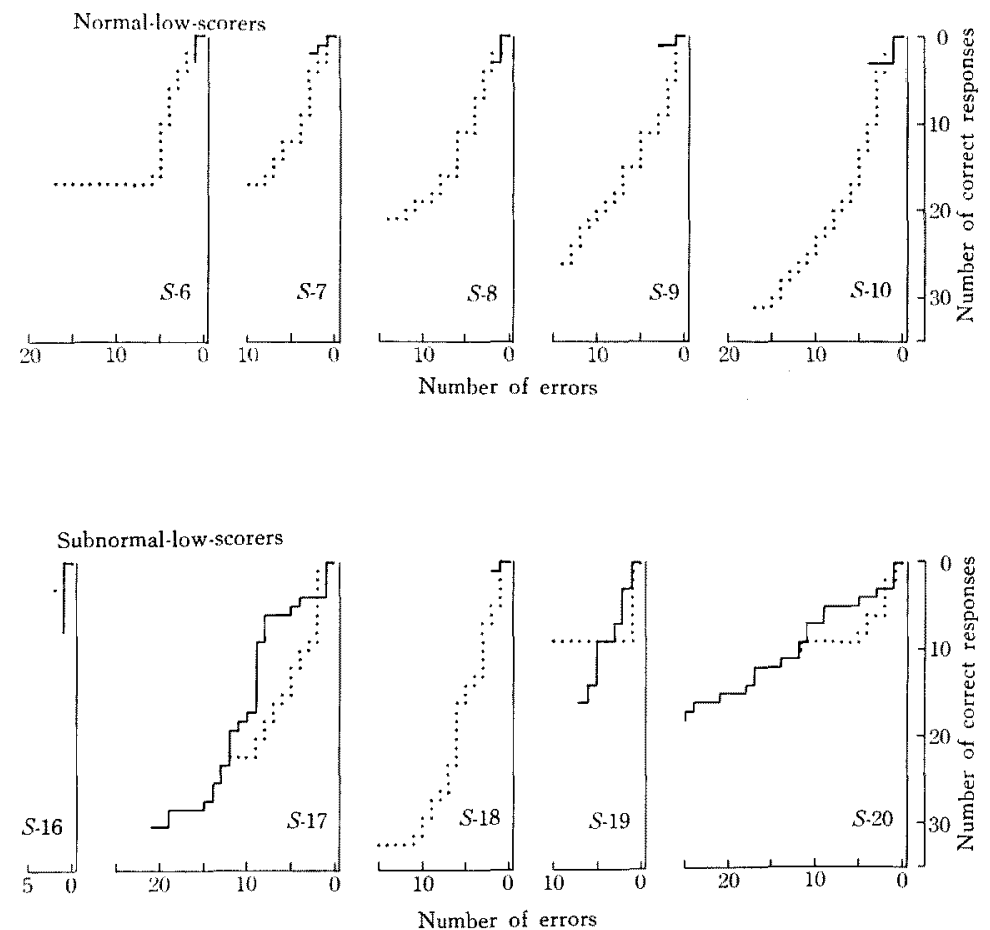

Fig. 1. Backward learning curves of individual low scorers required verbalization in original discrimination.

(- Discrimination, Reversal) 
well have its origin in the response pattern of individual subjects. In order to examine the individual learning process, the backward learning curves were depicted for all subjects. Highest consistency was obtained among the normal and subnormal subjects with high SCT scores. These children were highly effective in both original discrimination and reversal. Performance did not appear to be affected by the different treatment conditions. For the children with low SCT scores, however, clear differences were obtained between the treatment groups and between normal and subnormal subjects. Fig. 1 shows the backward 'learning curves of individual' subjects (normal and subnormal) with low SCT scores in the verbalization treatment. For the normal children, all five subjects strongly persisted in many wrong responses immediately after reversal, and then could rapidly reverse their responses (J-shaped curve). For subnormal children, on the other hand, three of the five subjects showed slow learning in original discrimination, and two subjects showed J-shaped curve in reversal.

\section{Disqussion}

The results reported here indicated that a child's score on SCT can be a good predictor of his performance of reversal shift. Because the performance of reversal shift is assumed to be determined by subject's mediation ability, it seems that the children with high SCT scores were able to use verbal mediation more efficiently than the children with low scores. Since SCT provided a sensitive mean in assessing a child's linguistic competence, it seems likely that the ability to use verbal mediation strongly linked to subject's linguistic development.

For the normal children, the results supported the O'Connor and Hermelin finding $(1959,1963)$ that reinforcement of verbalization leads to a stable and persistent response set which has an interfering effect on reversal shift. However, this was only true for children with low SGT scores presumably because of less mobile capacity to mediate. Evidence of this interference could be found in the individual badkward learning curves. In addition to more reversal trials, verbalization showed fairly the long runs of correct responses disrupted by intrusions of the old responses. High scores of correct responses with low scores of errors could be produced if the subject responded correctly with occasional intrusive errors. Conversely high scores of errors with low scores of correct responses could be produced if a subject persevered in a wrong response set. As can be seen in Fig. 1, the initial portion of the curves are presumed to be guided by the previously learned response set, and the rapidly ascending portion of the curves by the switched response set. For these children there was also some evidence suggesting that verbalization facilitated original discrimination $(\mathrm{A} \times \mathrm{C} \times \mathrm{D}$ interaction). It would seem possible that the child with low SCT scores is in a developmental stage of production deficiency. As Bem (1970) stated, the problem is not that child's verbalization have insufficient mediating or regulating power, but rather that he does not produce relevant verbalization in the first place. Asking the child to verbalize his response bases would serve to facilitate his performance in original learning because he has not the tendency to produce relevant verbalization spontaneously. However, since his verbal self-instructions could not be produced sufficiently, as O'Connor and Hermelin (1963) assumed, the previously appropriate verbal responses would have tended to persist as a stereotype in reversal. It may well be that the developmental period during which interfering response set can be established corresponds to the period of production deficiency. In view of these results, the present authors assume the following developmental stages in verbal mediation: (1) children are unable to mediate and to take advantage of verbalization because 
of their deficients in comprehension of the relations between words and situations (Comprehension deficiency), (2) children are able to comprehend words, but are less capable of producing the words at the appropriate times (Production cleficiency), and if children are asked to use the verbal mediators, they may fail to regulate their overt behavior by the verbal system in a changed stimulus situation, (3) children can produce the appropriate words but, as Stevenson (1970) pointed, still be unable to grasp the relation between what he was saying and what he was supposed to do (Mediational deficiency), and (4) children can use verbal mediators flexibly and regulate overt responses effectively.

For the subnormal children, the performances of high SCT scores were similar to those of high scoring normal children, but no definite statement could be made for low scorers because of the great individual differences. This experiment failed to replicate the O'Connor and Hermelin finding that subnormal children perform a discrimination reversal better than matched normal subjects. These disparate findings are almost certainly due to the use of different matching criteria. In the O'Connor and Hermelin study, children were matched on mental age. As the present authors were interested in the role of language in the control of motor behavior, it was reasonable to have matched children directly on the basis of their language development. Also the mental age range of subjects in the O'Connor and Hermelin study was large (3.4-6.7 years), hence it seems likely that the group was heterogeneous, including both high and low abilities of linguistic competence. Since this present study demonstrates that quite small developmental changes in language comprehension can bring about large changes in performance, conclusions derived from such a heterogeneous group are questionable.

In general, the finding that SCT scores can be used to separate children in dif- ferent mediating status suggests that SCT is useful as a research tool. However, it is required to analyse the theoretical relationship between verbal mediation and language comprehension more closely. It may be whether the two processes are directly related or develop in parallel. To examine such a theoretical relation between comprehension and mediation is an interesting problem.

\section{REFERENCES}

BEM, S. L. 1970 The role of comprehension in children's problem solving. Child Development, 2, 351-358.

Flaveli, J.H., Beach, D. R., \& Chinsky, J. M. 1966 Spontaneous verbal rehearsal in a memory task as a function of age. Child $D e$ velopment, 37, 283-299.

HeaL, W. H., \& Johnson, J. T. 1970 Inhibition deficits in retardate learning and attention. In N. R. Ellis (Ed.) International review of research in mental retardation, Vol. 4, New York and London: Academic Press.

Kendler, H.H., \& Kendler, T.S. 1962 Vertical and horizontal processes in problem solving. Psychological Review, 69, 1-16.

Kendler, T.S., Kendler, H.H., \& Wells, D. 1960 Reversal and nonreversal shifts in nursery school children. Journal of Comparative and Physiological Psychology, 53, 83-88.

Keeney, T.J., Cannizzo, S. R., \& Flaverl, J. H. 1967 Spontaneous and induced verbal rehearsal in a recall task. Child Development, 38, 953-966.

LURIA, A. R. 1961 The role of speech in the regulation of normal and subnormal behavior. New York: Liveright.

Maccoвy, E. E. 1964 Developmental psychology. Annual Revieze of Psychology, 15, 203250.

Mrttler, P., \& Wheldall, K. 1971 Language comprehension in the severely subnormal. Report of a symposium delivered to the annual conference of the British Psychological Society, Exeter, April 2nd.

O'Connor, N., \& Hermelin, B. 1959 Discrimination and reversal learning in imbeciles. Journal of Abnormal and Social Psychology, 59, $409-413$.

O'Connor, N., \& Hermelin, B. 1963 Speech 
and thought in severe subnormality. London: Pergamon.

REESE, H. W. 1962 Verbal mediation as a function of age level. Psychological Bulletin, 59, 502-509.
Stevenson, H.W. 1970 Learning in children. In P. H. Mussen (Ed.) Carmichael's manual of child psychology, Vol. 1, New York: Academic Press.

(Received July 7, 1975) 